\title{
Juvenile Nasopharyngeal Angiofibroma: Changing Paradigms in Management
}

\author{
Vijay Bhalla, ${ }^{1}$ Ramakrishnan Narayanaswamy ${ }^{1}$
}

\begin{abstract}
Introduction
Juvenile Nasopharyngeal Angiofibroma (JNA) is a tumor of young and adolescent males. It is a benign vascular tumor arising from the spheno-palatine foramen. It is best managed surgically at present by endoscopic methods with or without pre-operative embolization. Tumor attributes like intracranial extent and residual vascularity after embolization need to be assessed preoperatively before undertaking endoscopic surgery, in order to reduce surgical blood loss and morbidity.

Materials and Methods

Twenty-three cases of JNA $(n=23)$ were operated endoscopically at a tertiary level military hospital. They were staged with the Snyderman staging system. Demographic variables including stage wise management were brought out with intraoperative time and blood loss recorded for different stages.

$\underline{\text { Results }}$

The intraoperative surgical time, intra-operative blood loss and recurrence/residual rates were compared with similar studies in existing literature and correlated well.

Conclusion

Endoscopic Endonasal approach to JNA is now a well-established technique. With improvements in embolization techniques and better instrumentation like HD camera systems, endo-bipolar cautery, Coblation and endo-liga clips and neuro-navigation, better visualization and better haemostatis can be achieved, resulting in significant reduction in the morbidity and improvement in surgical results.

Kevwords
\end{abstract}

$\underline{\text { ABSTRACT }}$

Angiofibroma; Endoscopic Surgery

$\mathrm{J}^{\mathrm{s}}$ uvenile Nasopharyngeal Angiofibroma (JNA) is a benign vascular tumor of the nose and nasopharynx in young and adolescent males, which is primarily managed surgically. Due to the peculiar nature of the tumor, propensity to spread through various foramina, fissures, spaces and tendency for post surgical residual persistence of tumor; it poses a formidable challenge to ENT surgeons, who are managing these tumors. These tumors are locally aggressive, erode bones and can spread outside the confines of the nose and nasopharynx to involve the paranasal sinuses,pterygo-palatine, infratemporal, parapharyngeal spaces, orbit and so also intracranially.

The standard of care for decades and centuries has been open surgical techniques with major morbidity including blood loss and recurrences. ${ }^{1}$ Over a period of time, these open surgeries have been supplemented with angiography and embolization, which has reduced the per-operative blood loss considerably. ${ }^{2}$ Further, the advent of endoscopic surgery has improved our knowledge and behavior of these tumors and they can now be excised with much greater precision with reduction in the peroperative blood loss and residual tumor. ${ }^{3}$ This article gives an overview of the endoscopic management of JNAs, at a tertiary level military hospital.

\section{Materials and Methods}

This is a retrospective cohort study of 23 cases of JNA, managed endoscopically at a tertiary level military hospital during the period 2011 to 2016 . The aim of this study is to evaluate the advantagesof endoscopic management technique for JNAs and validate its

1 - Department of ENT, Command Hospital(EC),Kolkata

\section{Corresponding author:}

Dr Ramakrishnan Narayanaswamy

email: drnramak5632@gmail.com 
advantages. All the patients underwent CECT scans for determining the extent of spread with bony erosion. The stage of tumors considered for endoscopic excision was based on the Snyderman classification ${ }^{4}$ for JNAs (Table I). Contrast enhanced MRI was done in all cases to detect intracranial and intradural spread of tumor. Of the large tumors, only those that had intracranial but extradural spread were included in the study. Patients of Grade $\mathrm{V}$ who may require craniotomy for intra-dural involvement of tumor were excluded, as only those cases that had undergone endoscopic surgery, were

Table I: Snyderman et al. classification of JNA

\begin{tabular}{|c|c|}
\hline I & Nasal cavity, pterygopalatine fossa \\
\hline II & $\begin{array}{c}\text { Paranasal sinuses, lateral pterygopalatine } \\
\text { fossa; no residual vascularity }\end{array}$ \\
\hline III & $\begin{array}{c}\text { Skull base erosion, orbit, infratemporal } \\
\text { fossa; no residual vascularity }\end{array}$ \\
\hline IV & $\begin{array}{r}\text { Skull base erosion, orbit, infratemporal } \\
\text { fossa; residual vascularity }\end{array}$ \\
\hline V M & $\begin{array}{r}\text { Intracranial extension, residual vascularity; } \\
\text { M: medial extension }\end{array}$ \\
\hline V L & $\begin{array}{r}\text { Intracranial extension, residual vascularity; } \\
\text { L: lateral extension }\end{array}$ \\
\hline
\end{tabular}

included in the study.

Operative Technique: All the patients underwent preoperative angiography and embolization 24 hours prior to the surgery. Residual vascularity after angiography and embolization was noted.

A four-hand technique for endoscopic removal of JNAs was used. The same surgeon operated all the cases. Inferior and Middle turbinates were excised to create more endoscopic space. Endoscopic medial maxillectomy was performed and posterior wall of maxilla was exposed and removed. The main trunk of the Internal maxillary artery was identified and vascular control achieved either with Liga clips or with endobipolar cautery.

The tumor was gradually mobilized from all the attachments to achieve complete removal. In view of the embolization and resultant shrinkage of the tumor, the cancellous bones of the pterygoid base, including
Vidian canal and basisphenoid, which are likely to harbor residual tumor, ${ }^{5}$ were drilled out in all cases, to remove any tumor remnants. All patients were assessed for per-operative blood loss.

Post-operatively, all the patients underwent anterior nasal packing with Merocel for $48 \mathrm{hrs}$. All patients were given injectable antibiotics for 2 days only after which they were given oral antibiotics. All patients underwent an MRI after $72 \mathrm{hrs}$ post-operatively, for detecting any residual tumor left behind. They were further followed up to look for residual tumor after six months and then at one-year post-op.

Variables analyzed included patient age, tumor stage, preoperative embolization with residual vascularity, surgical approach, duration of surgery, volume of intraoperative bleeding, length of hospitalization, residual/recurrence.

\section{Results}

All were male patients in the age range of 09 to 19 years (Average age: 13.91 yrs). The variables assessed are given in Table II. As per the Snyderman staging system the distribution of the cases was as given in Table III.

Tumors involving the paranasal sinuses and infratemporal fossa are shown in Fig. 1. 21/23 (91\%) patients showed tumor blush feeding from the External Carotid Artery, which were embolized with no residual vascularity (Fig.2). 02/23 patients (9\%) with Stage IV tumor showed residual vascularity, due to supply from the ipsilateral Internal Carotid Artery (Fig.3 and 4).

The average duration of surgery stage wise is as follows- Stage I- $100 \mathrm{~min}$, StageII-160 min, StageIII-265 min, and Stage-IV-315 min. The average intraoperative blood loss is as follows -Stage I- 200 ml, Stage II- 363 ml, Stage III- 586 ml, Stage IV- 1300 $\mathrm{ml}$. (Table IV). Both the patients with Stage IV tumors underwent a staged resection due to large tumors with residual vascularity (Fig. 4). Their combined average blood loss in the staged surgery was $1300 \mathrm{ml}$ each, in two surgeries put together. The data distribution in Table IV is negatively skewed due to multiple surgeries in Stage IV disease.

Residual tumour was detected on MRI within one 
Table II: Variables assessed vide the master chart

\begin{tabular}{|c|c|c|c|c|c|c|c|c|c|}
\hline 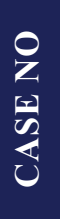 & $\sum_{\substack{0 \\
0}}^{\frac{\sigma}{2}}$ & 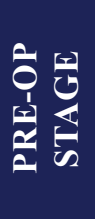 & 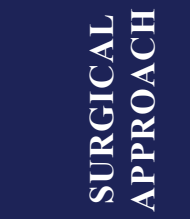 & 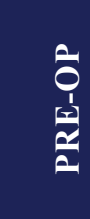 & 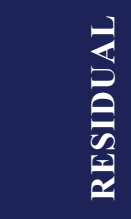 & 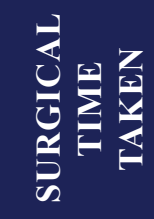 & 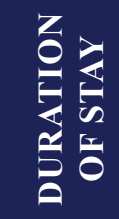 & 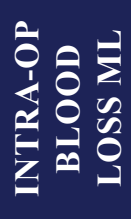 & 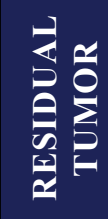 \\
\hline 1 & 12 & II & Endoscopic & + & - & $31 / 2$ hrs & 3 days & 400 & - \\
\hline 2 & 11 & I & Endoscopic & + & - & $11 / 2 \mathrm{hrs}$ & 3 days & 200 & - \\
\hline 3 & 16 & II & Endoscopic & + & - & $21 / 2 \mathrm{hrs}$ & 4 days & 350 & - \\
\hline 4 & 18 & III & Endoscopic & + & - & 5 hrs & 5 days & 450 & - \\
\hline 5 & 13 & III & Endoscopic & + & - & 4 1 $1 / 2 \mathrm{hrs}$ & 5 days & 500 & - \\
\hline 6 & 19 & II & Endoscopic & + & - & $3 \mathrm{hrs}$ & 3 days & 400 & - \\
\hline 7 & 10 & I & Endoscopic & + & - & 2 hrs & 3 days & 250 & - \\
\hline 8 & 14 & III & Endoscopic & + & - & 4 1 $1 / 2 \mathrm{hrs}$ & 5 days & 650 & + \\
\hline 9 & 13 & II & Endoscopic & + & - & $21 / 2 \mathrm{hrs}$ & 4 days & 300 & - \\
\hline 10 & 17 & I & Endoscopic & + & - & 1 1/2 hrs. & 2 days & 150 & - \\
\hline 11 & 19 & III & Endoscopic & + & - & $4 \mathrm{hrs}$ & 5 days & 550 & - \\
\hline 12 & 16 & III & Endoscopic & + & - & $41 / 2 \mathrm{hrs}$ & 5 days & 600 & - \\
\hline 13 & 9 & II & Endoscopic & + & - & $31 / 2 \mathrm{hrs}$ & 4 days & 400 & - \\
\hline 14 & 10 & I & Endoscopic & + & - & $2 \mathrm{hrs}$ & 2 days & 150 & - \\
\hline 15 & 16 & $1 \mathrm{~V}$ & $\begin{array}{l}\text { Endoscopic } \\
\text { Staged }\end{array}$ & + & + & $5 \mathrm{hrs}$ & 5 days & 1200 & + \\
\hline 16 & 17 & II & Endoscopic & + & - & 3 hrs & 4 days & 300 & - \\
\hline 17 & 13 & I & Endoscopic & + & - & $11 / 2 \mathrm{hrs}$ & 2 days & 250 & - \\
\hline 18 & 11 & III & Endoscopic & + & - & 4 hrs & 4 days & 650 & - \\
\hline
\end{tabular}


Table II: Variables assessed vide the master chart (Contd.)

\begin{tabular}{|c|c|c|c|c|c|c|c|c|c|}
\hline $\begin{array}{l}0 \\
Z \\
0 \\
0 \\
0 \\
0 \\
0\end{array}$ & 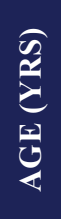 & 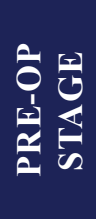 & 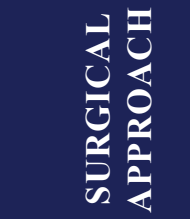 & 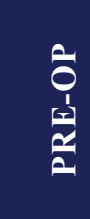 & 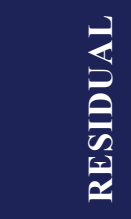 & 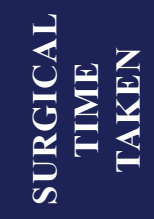 & 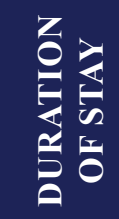 & 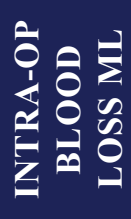 & 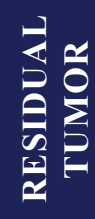 \\
\hline 19 & 10 & I & Endoscopic & + & - & $13 / 4 \mathrm{hrs}$ & 2 days & 200 & - \\
\hline 20 & 19 & II & Endoscopic & + & - & $2 \mathrm{hrs}$ & 3 days & 300 & - \\
\hline 21 & 16 & IV & $\begin{array}{l}\text { Endoscopic } \\
\text { Staged }\end{array}$ & + & + & $51 / 2$ hrs & 6 days & 1400 & + \\
\hline 22 & 12 & II & Endoscopic & + & - & $21 / 2 \mathrm{hrs}$ & 4 days & 450 & - \\
\hline 23 & 9 & III & Endoscopic & + & - & $41 / 2 \mathrm{hrs}$ & 5 days & 700 & + \\
\hline
\end{tabular}

year in $04(17 \%)$ patients- Stage III-02 (8.5\%) and Stage-IV - 02(8.5\%). In all the cases, residual tumor was found in the region of the basisphenoid.

These were advanced tumors, which were also operated endoscopically, in a staged manner. The figures of residual tumor corroborate with a similar study by Nicolai. The average blood loss and residual tumor rate also statistically corroborated well with other studies given at Table $\mathrm{V}$.

Table III: Distribution of tumor as per Snyderman staging system for JNA

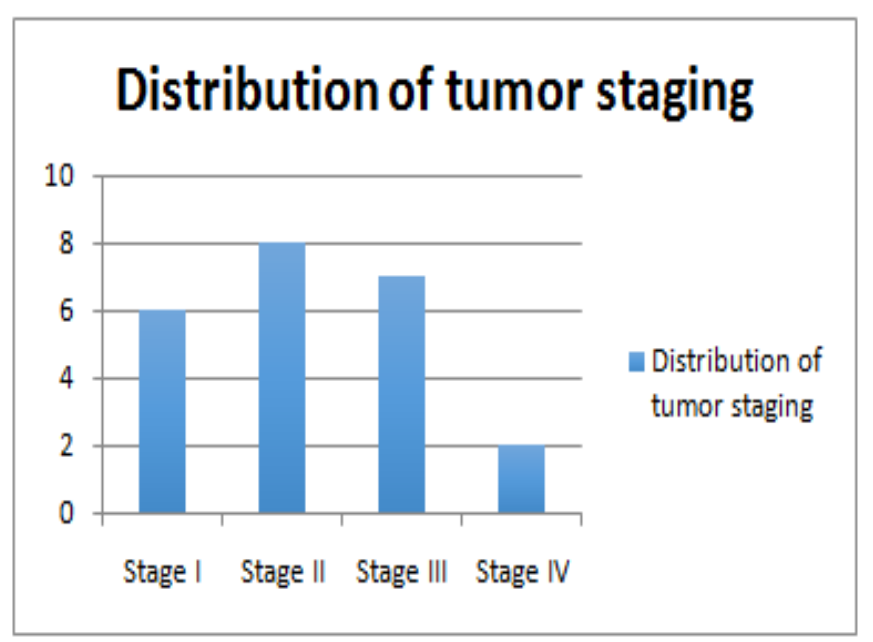

\section{Discussion}

JNA is a benign vascular tumor of young adolescent males, which is hypothesized to be arising from the spheno-palatine foramen. However, there are reports proposing its site of origin from the vidian canal also. It spreads by locally expanding and eroding bony confines and involving the paranasal sinuses, pterygopalatine and infra-temporal fossae. It can also spread intracranially through the skull base foramina like foramen ovale, parasellar areas around the cavernous

Table IV: Intra-operative Blood loss

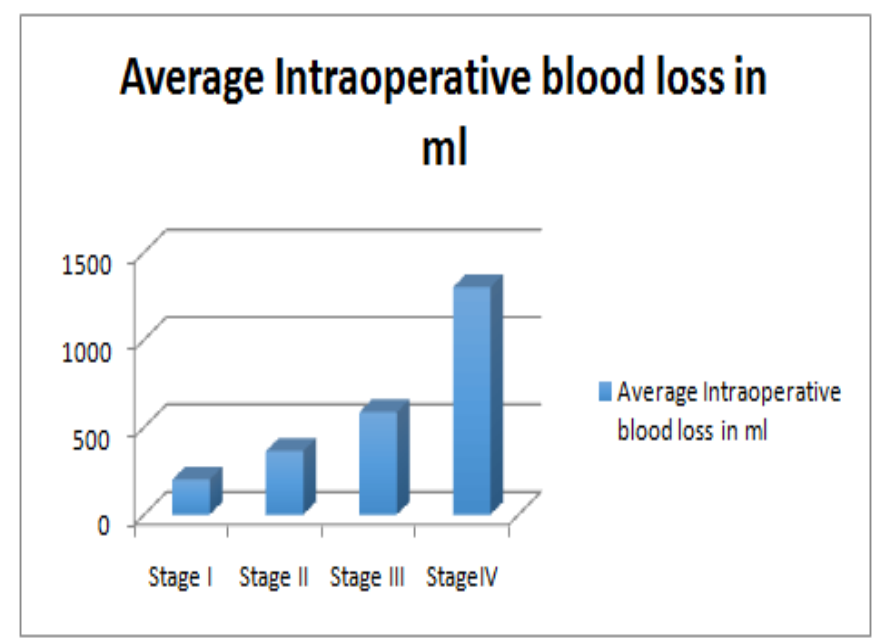


sinuses.

JNA has conventionally been classified and staged based on Fisch ${ }^{6}$ staging system or the Radkowski ${ }^{7}$ staging system. Both these staging systems are good staging systems for open procedures. They were proposed and followed during the pre-endoscopic surgery era for JNA. Ever since JNAs have been operated with endoscopic techniques, it is felt that the above staging systems does not offer the kind of information required for endoscopic surgeon, like degree of vascularity, whether it had blood supply from one or both ECA or ICA and whether there was a residual vascularity in the tumor after embolization. To meet this requirement, the classification used for our study was the Snyderman staging system.

JNAs have a tendency to enter into the skull base canals/foramina and spread along the sub-periosteal planes. Therefore, in order to achieve a total removal, the cancellous area of the skull base i e. pterygoid wedge and basisphenoid need to be adequately drilled out. ${ }^{8}$ The recurrence/residual tumor rates in open surgical approaches were reported in the range of $36-40 \%$ in 1990s. ${ }^{9}$ Later in 2008, Danesi et al reported excellent results on open procedures to 13.5 to $18.2 \%{ }^{10}$

The tumor usually takes its blood supply from the Internal Maxillary Artery (IMA). However, in cases of contralateral spread, it can also take supply from the contralateral IMA. Bilateral vascular supply in around

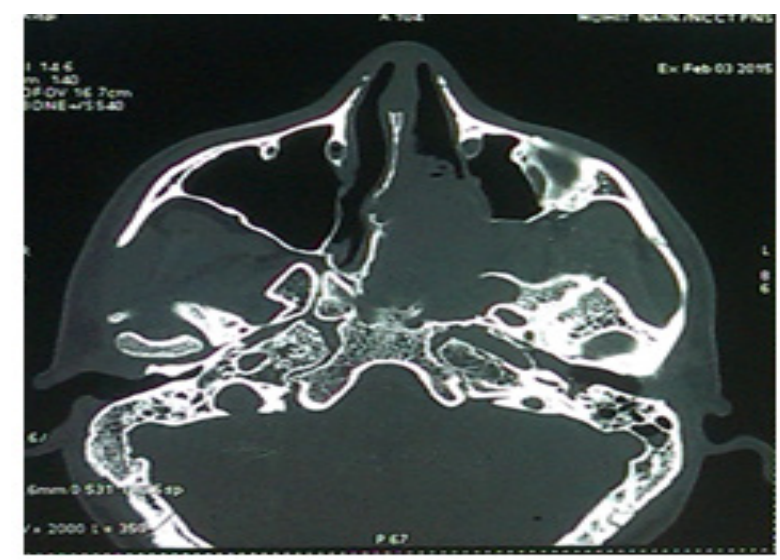

(a)
$36 \%$ has been reported by $\mathrm{Wu}$ et al. ${ }^{11}$ When it spreads intracranially, it can take supply from the branches of the Internal Carotid Artery (ICA), most commonly from the meningo-hypophyseal trunk or its branches.

The traditional surgical methods commonly performed to remove JNA were once transpalatal, transpharyngeal, transfacial through lateral rhinotomy, midfacial degloving, and Le Fort I osteotomy, apart from infratemporal and subtemporal lateral approaches. ${ }^{12,13}$ Improvements in the imaging and embolization techniques have improved the evaluation and reduced the per-operative blood loss, which have greartly improved the rates of complete removal. Further, a paradigm shift from open techniques to endoscopic surgery for not so extensive tumours have also improved the visualization and helped in achieving good per-operative vascular control for these tumors, thereby improving the surgical results and reducing morbidity, due to open surgical techniques. Endoscopic excision of JNA was first reported in $1998 .{ }^{14}$

Even large angiofibromas with intracranial extension and residual vascularity can be successfully managed by a skull base team using endoscopic techniques. ${ }^{15}$ Similar results were obtained in other series by Snyderman, who have operated by the same surgical technique and followed the same tumor staging system. ${ }^{16}$ Among all the staging systems proposed till now, the staging system which addresses the most essential tumour attributes

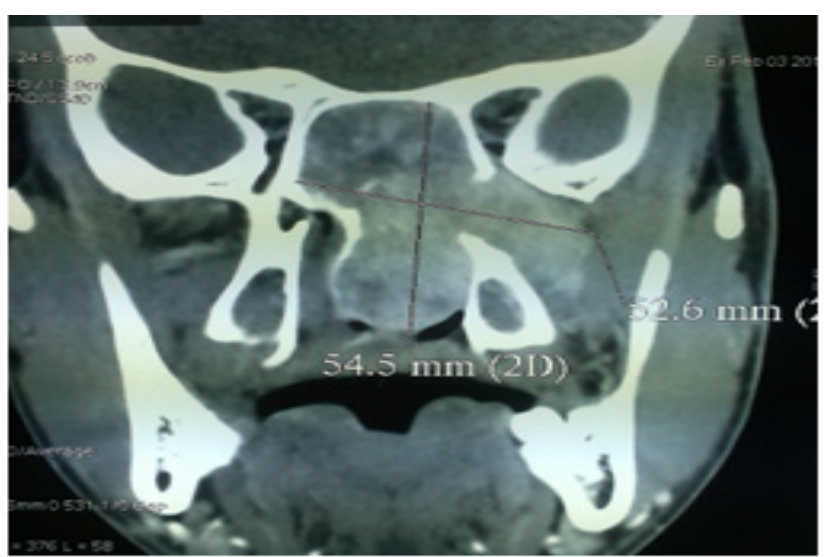

Fig. 1. (a). NCCT axial view of a JNA extending through the pterygopalatine fossa to involve the infratemporal fossa (Stage - III). (b) Contrast enhanced coronal CT showing the same tumor lateral to the pterygoid plates into the infratemporal fossa. 


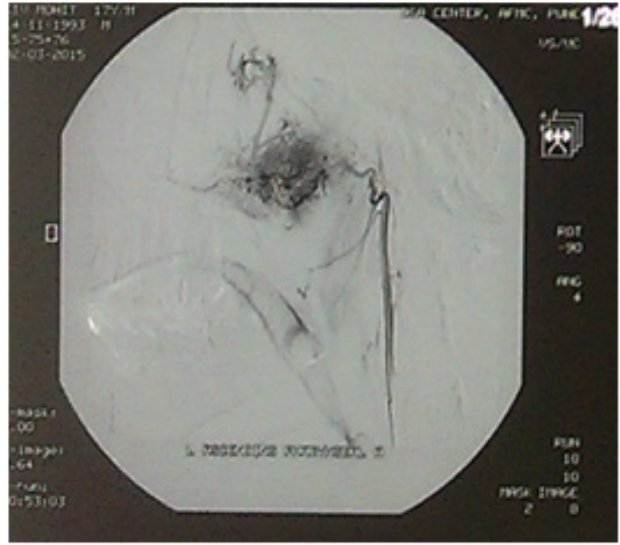

(a)

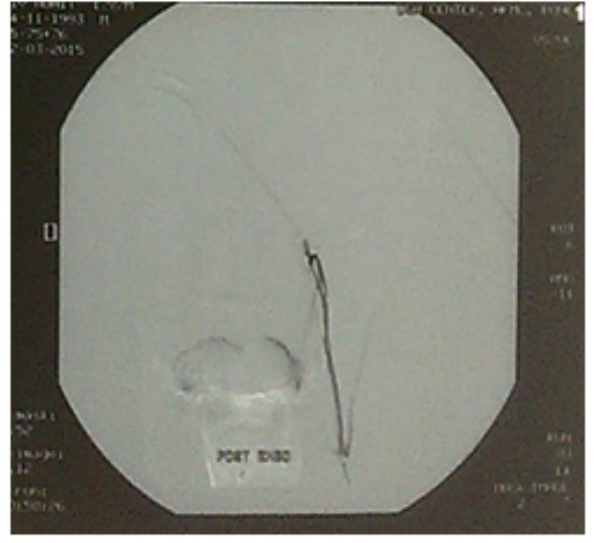

(b)

Fig. 2. (a) Pre-embolization angiography showing the tumor blush from the Lt maxillary artery. (b) Post-embolization with glue showing complete disappearance of the tumor blush with no residual vascularity (Stage-III)

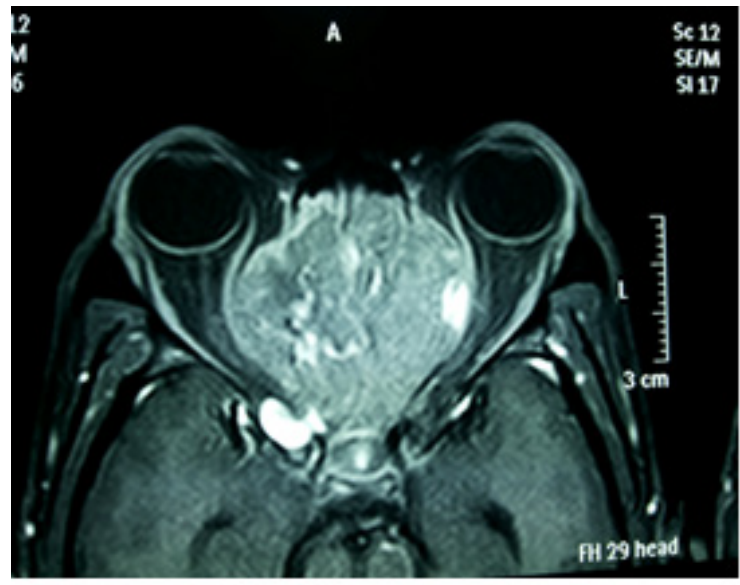

(a)

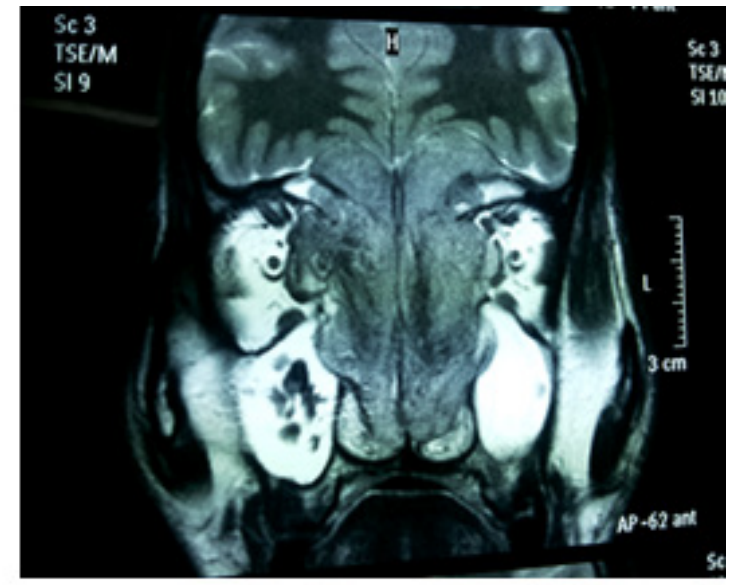

(b)

Fig. 3. Gadolinium enhanced MRI showing a large JNA extending into both the orbits and also intracranial extension but extradural

for endoscopic surgery like skull base extension and residual tumour vascularity is the one proposed by the University of Pittsburgh Medical Center. ${ }^{17}$ Availability of better and safe embolization materials have also reduced the morbidity considerably. Direct Percutaneous Embolization directly into the tumor, is now available especially for those tumors, which have a dual supply from both the carotid systems, where endovascular embolization into both carotids systems cannot be done. ${ }^{18}$

Radiation has been used to treat JNAs in far advanced tumors, adjuvant in unresectable tumors, extensive intracranial extension and residual tumours in critical areas such the ICA, cavernous sinus, dura and the optic nerve. ${ }^{19}$ However, there exists a reported risk of sacomatoid transformation ${ }^{20}$ or radiation induced neoplasms in a long term follow-up. The role of androgen receptor blocker flutamide been investigated and it has shown regression in a series of 20 advanced staged JA, in postpuberal patients. ${ }^{21}$

\section{Conclusion}

Endoscopic Endonasal approach for excision of JNA is now a well-established technique. With improvements in embolization techniques and better instrumentation 


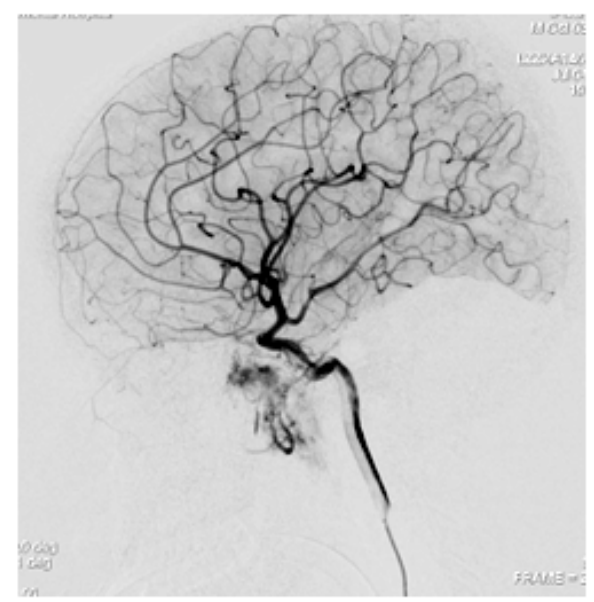

(a)

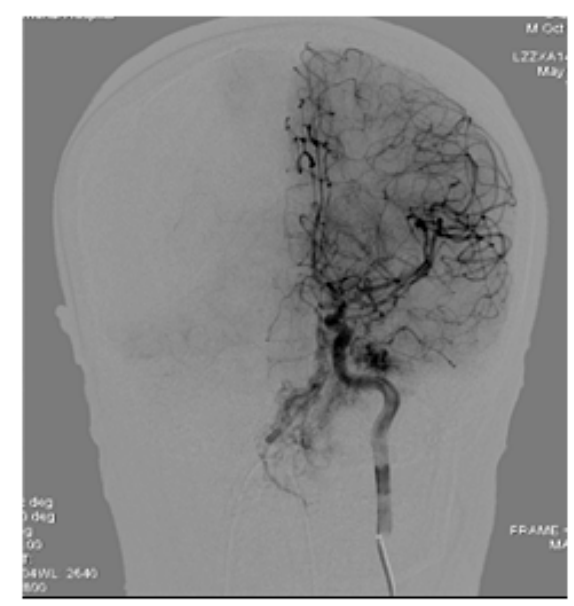

(b)

Fig. 4. Sagittal (a) and coronal (b) views of angiogram showing residual vascularity due to additional blood supply to tumor from the meningo - hypophyseal trunk of the ICA. (Stage - IV)

like HD camera systems, endo-bipolar cautery, Coblation, Endo-Liga clips and neuro-navigation, better

to be addressed intra-operatively, to reduce the rates of recurrence.

Table V: Comparative data in other studies with endoscopic excision of JNA

\begin{tabular}{|c|c|c|c|}
\hline AUTHOR & NO OF CASES & $\begin{array}{c}\text { AVERAGE BLOOD } \\
\text { LOSS }\end{array}$ & RESIDUAL TUMOR \\
\hline Ardehali $^{22}$ & 47 & $770 \mathrm{ml}$ & $19.10 \%$ \\
\hline Roger G $^{23}$ & 20 & $350 \mathrm{ml}$ & Nil \\
\hline Pryor $^{24}$ & 6 & $225 \mathrm{ml}$ & Nil \\
\hline Kopec $^{25}$ & 10 & $250 \mathrm{ml}$ & $10 \%$ \\
\hline Cloutier $^{26}$ & 72 & $380 \mathrm{ml}$ & $8.30 \%$ \\
\hline Present Study & 23 & $612 \mathrm{ml}$ & $17 \%$ \\
\hline
\end{tabular}

visualization and better haemostatis can be achieved resulting in significant reduction in the morbidity. Newer staging systems have helped in assessing the tumor with respect to intracranial extension and intratumoral blood supply and embolization results, which is so very important in predicting the surgical course, likely intraoperative blood loss and likelihood of residual disease. Some of the surgical corners of consternation like pterygoid base and basisphenoid need

\section{References}

1. Andrade NA, Pinto JA, Nóbrega MO. Exclusively endoscopic surgery for juvenile nasopharyngeal angiofibroma. Otolaryngol Head Neck Surg. 2007; 137:492-6

2. Lutz J, Holtmannspötter M, Flatz W. Preoperative Embolization to Improve the Surgical Management and Outcome of Juvenile Nasopharyngeal Angiofibroma (JNA) in a Single Center: 10Year Experience; Clin Neuroradiol. (2016) 26: 405

3. Lund VJ, Stammberger H, Nicolai P. European position paper 
on endoscopic management of tumours of the nose, paranasal sinuses and skull base. Rhinol Suppl. 2010; 22:1-143

4. Snyderman CH, Pant H, Carrau RL, Gardner P. A new endoscopic staging system for angiofibromas. Arch Otolaryngol Head Neck Surg. 2010; 136:588-94

5. Mann WJ, Jecker P, Amedee RG. Juvenile angiofibromas: changing surgical concept over the last 20 years. Laryngoscope 2004; 114:291-3

6. Andrews JC, Fisch U, Valavanis A, Aeppli. The surgical management of extensive nasopharyngeal angiofibromas with the infratemporal fossa approach. Laryngoscope 1989; 99:42937

7. Radkowski D, McGill T, Healy GB. Angiofibroma- Changes in staging and treatment. Arch Otolaryngol Head Neck Surg. 1996; 122(2): 122-9

8. Howard DJ, Lloyd G, Lund V. Recurrence and its avoidance in juvenile angiofibroma. Laryngoscope. 2001; 111(9): 1509-11

9. Lloyd G, Howard D, Phelps P, et al. Juvenile angiofibroma: the lessons of 20 years of modern imaging. Journal of Laryngology and Otology 1999; 113(2):127-34

10. Danesi G, Panciera DT, Harvey RJ. Juvenile nasopharyngeal angiofibroma: evaluation and surgical management of advanced disease. Otolaryngology_-Head and Neck Surgery 2008; 138(5):581-6

11. Wu AW, Mowry SE, Vinuela F. Bilateral vascular supply in juvenile nasopharyngeal angiofibromas. Laryngoscope 2011; 121(3):639-43

12. Scholtz AW, Appenroth E, Kammen-Jolly K. Juvenile nasopharyngeal angiofibroma: management and therapy. Laryngoscope 2001;111(4): 681-7

13. Yiotakis I, Eleftheriadou A, Davilis D. Juvenile nasopharyngeal angiofibroma stages I and II: a comparative study of surgical approaches. International Journal of Pediatric Otorhinolaryngology 2008; 72(6):793-800

14. Mitskavich MT, Carrau RL, Snyderman CH. Intranasal endoscopic excision of a juvenile angiofibroma. Auris Nasus Larynx 1998; 25(1): 39-44

15. Snyderman CH, Pant H. Endoscopic Management of Vascular Sinonasal Tumors, Including Angiofibroma. Otolaryngol Clin of North Am. 2016;49 (3):791-807
16. Hackman T, Snyderman CH, Carrau R, Kassam A. Juvenile nasopharyngeal angiofibroma: The expanded endonasal approach.Am J Rhinol Allergy. 2009; 23(1):95-9

17. Rowan NR, Zwagerman NT, Heft-Neal ME. Juvenile Nasal Angiofibromas: A Comparison of Modern Staging Systems in an Endoscopic Era. J Neurol Surg B Skull Base 2017; 78 (1): 63-7

18. Borota L, Mahmoud E, Nyberg C. Combined percutaneous and transarterial devascularisation of juvenile nasopharyngeal angiofibroma with protection of internal carotid artery: A modification of the technique. Interv Neuroradiol. 2015; 21(3): 390-6

19. Nicolai P, Villaret AB, Farina D. Endoscopic surgery for juvenile angiofibroma: a critical review of indications after 46 cases. American Journal of Rhinology and Allergy 2010; 24(2):e67-e72

20. Makek MS, Andrews JC, Fisch U. Malignant transformation of a nasopharyngeal angiofibroma. Laryngoscope 1989; 99(10):1088-92

21. Thakar A, Gupta G, Bhalla AS. Adjuvant therapy with flutamide for presurgical volume reduction in juvenile nasopharyngeal angiofibroma. Head and Neck 2011; 33(12):1747-53

22. Ardehali MM, Samimi Ardestani SH, Yazdani N, Goodarzi H, Bastaninejad S. Endoscopic approach for excision of juvenile nasopharyngeal angiofibroma: complications and outcomes. Am J Otolaryngol. 2010; 31(5):343-9

23. Roger G, Tran Ba Huy P, Froehlich P, Van Den Abbeele T, Klossek JM, Serrano E, et al. Exclusively endoscopic removal of juvenile nasopharyngeal angiofibroma: trends and limits. Arch Otolaryngol Head Neck Surg. 2002; 128(8):928-35

24. Pryor SG, Moore EJ, Kasperbauer JL. Endoscopic versus traditional approaches for excision of juvenile nasopharyngeal angiofibroma. Laryngoscope 2005; 115(7):1201-7

25. Kopeć T, Borucki Ł, Szyfter W. Fully endoscopic resection of juvenile nasopharyngeal angiofibroma - own experience and clinical outcomes. Int J Pediatr Otorhinolaryngol. 2014; 78(7):1015-8

26. Cloutier T, Pons Y, Blancal JP, Sauvaget E, Kania R, Bresson D et al. Juvenile nasopharyngeal angiofibroma: does the external approach still make sense? Otolaryngol Head and Neck Surg. 2012; 147 (5): 958-63. 